\title{
UNA COHORTE HISPANA EN EL DESIERTO DEL NÉGUEV, A LA LUZ DE UN HALLAZGO RECIENTE
}

\author{
POR
}

PAU FIGUERAS

Universidad Ben Gurión del Néguev. Beersheva, Israel

PALABRAS CLAVE: Relieve romano. Epigrafía latina. Epigrafía griega. Inscripciones votivas. Atenea. Cohors V Hispanorum. Siglos II-IV d.C.

KEY WORDS: Roman relief. Latin epigraphy. Greek epigraphy. Votive inscriptions. Athenea. Cohors V Hispanorum. $2^{\text {nd }}-4^{\text {th }}$ centuries $\mathrm{AD}$.

\section{RESUMEN}

Una estatua fragmentaria con inscripción dedicatoria bilingüe, encontrada en el desierto del Néguev, arroja nueva luz sobre la presencia militar romana en el antiguo territorio nabateo. Por sus atributos, la estatua identifica a la diosa griega de la guerra con la diosa nabatea Alat. La parte latina de la inscripción menciona a un soldado de la muy poco conocida cohors VI Hispanorum.

\section{SUMMARY}

A fragmented statue with a bilingual inscription, found in the Negev desert, throws new light on the Roman military presence in the ancient Nabataean kingdom. The statue's features identify the Greek war goddess with the Nabataean goddess Alat. The Latin inscription mentions a soldier from the very little known Cohors VI Hispanorum.

\section{INTRODUCCIÓN}

Poco se sabe de la presencia de soldados hispanos en el Medio Oriente durante los últimos siglos del imperio romano. Por eso, el fortuito hallazgo de los fragmentos de una estatua de la diosa Atenea, con una inscripción atestiguando por primera vez su presencia en pleno desierto del Néguev, tiene que despertar la curiosidad de cuantos se interesan por tal tema ${ }^{1}$. Dichos fragmentos de estatua fueron ha-

1 Ignoramos la causa de que tal hallazgo no haya sido todavía publicado oficialmente por los responsables del patrimonio arqueológico de Israel. Por conocerlo de primera mano, nosotros nos referimos directamente a él en una conferencia pronunciada en Oxford en 1992 y publicada luego, pero sin reproducción gráfica de la estatua y la inscripción, en la revista inglesa $A R A M$ (Figueras 1992). Que sepamos, la única reacción a esa publicación fue la mención y reproducción del texto que de ella se hizo en L'année épigraphique (1993: 500, $\mathrm{n}^{\circ}$ 1652). El presente artículo representa una nueva redacción de aquella conferencia, a la que añadimos, sin embargo, un dibujo de la estatua en cuestión (fig. 1). La estatua se halla actualmente almacenada en los depósitos de llados por unos niños entre las tumbas de un cementerio beduino situado junto a las ruinas de un pequeño fuerte romano. El nombre actual del lugar, 'Ein Saharonim, indica la presencia de un manantial. Es natural que los nabateos, pueblo árabe dedicado al comercio, aprovecharan este sitio para hacer un alto en su camino, la llamada «Ruta de las Especias» ${ }^{2}$, que unía su capital, la ciudad de Petra, con el puerto de Gaza, atravesando el desierto del Néguev. Una vez anexionado el reino nabateo al Imperio en 106/ 7 d.C., parece que los romanos establecieron allí una guarnición. Por lo tanto, nuestra estatua, pagana y con inscripción en griego y en latín, no puede fecharse más que en los siglos II - IV d.C., es decir, durante el período que va entre el final de la dominación de los nabateos (106/7 d.C) y la introducción del cristianismo en tiempos de Constantino. Su valor artístico es prácticamente nulo, pues se trata de una pobre imitación local de la representación clásica de Atenea, tal como es conocida en Oriente por otras estatuas de la diosa griega de la guerra. Su importancia deriva principalmente del valor documental que podemos atribuirle. En efecto, nuestra estatua constituye un claro testimonio de la presencia militar romana en el Néguev, presencia militar que es justamente la de una cohorte hispana.

Antes de comentar este doble testimonio, sin embargo, queremos destacar el hecho de que la diosa griega de la guerra a la que daban culto los soldados romanos establecidos en la región, era identificada por los nabateos locales con Alat, la diosa árabe de la guerra. Es un hecho conocido que el culto de Atenea era practicado no sólo en el norte, este y sur de Siria, sino también en las ciudades de la Decápolis romana. Estatuas de la diosa han sido halladas en la ciudades de Bet-Sheán (Escitópolis) y Ammán (Filadelfia), aunque la diosa Atenea no aparece en la numismática local. La estatua descubierta en el desierto del Néguev suscita algunas cuestiones acerca de su culto, al mismo tiempo que ilustra el hecho (por cierto muy poco realzado por los investigadores) del culto practicado a las divini-

la Autoridad de Antigüedades de Israel, en el Museo Rockefeller de Jerusalén.

2 Véase Negev 1966. 
dades locales por parte de las autoridades romanas $y$, en especial, por los oficiales del ejército imperial. En efecto, conocemos casos de soldados romanos que, en el curso de su servicio militar en las provincias orientales, erigieron estatuas a los dioses del lugar. M.Sartre (1984) publicó una inscripción griega de Shaqqa (Maximinianópolis, en Bashán), en la que un centurión dedica una estatua a la 'Tyche Megale' de la ciudad, en su nombre y el de sus hijos. Refiriéndose a ella, Banjamín Isaac hace notar que no se trata de un veterano y que, por lo tanto, podría muy bien ser un oficial local. «Si lo fuera - dice Isaac-, la inscripción demuestra un cierto grado de integración social» (Isaac 1990: 135-136). En este contexto, uno no puede olvidar el caso mejor conocido del centurión romano de Cafarnaúm en tiempo de Jesús, «amigo de nuestro pueblo», según la expresión que se pone en boca de los judíos locales, quien contribuyó generosamente a la construcción de su sinagoga (Lucas 7: 1-5).

Como ya hemos apuntado arriba, la diosa de la guerra, al igual que muchas otras divinidades griegas, había sido asimilada a Alat por las nabateos y también por otros grupos árabes (tamudeos, entre otros) que se habían asentado en territorio sirio. Lo más probable es que esto sucediera ya antes de la anexión romana del reino nabateo y de su transformación en la provincia Arabia del imperio. Lo mismo sucedió más al norte, en Palmira, donde el culto de Atenea y su identificación con Alat estaban tan arraigados entre la población en el siglo III d.C. que, en las monedas, el hijo de la reina Zenobia se refiere oficialmente a sí mismo con los dos nombres de Uaballatos y Athenodoros, esto es, el «don de Alat» (Wahab Allat) y «dọn de Atenea» (Mildenberg 1990: 67). La misma identificación de Atenea con Alat es atestiguada por la epigrafía, no sólo en Palmira (Kindler 1983: 57) sino incluso en un lugar tan remoto como Córdoba en España, del que Franz Cumont mencionaba ya una inscripción griega del período romano en la que se lee «Atenea-Alat» $(\mathrm{Cu}-$ mont 1924: 345).

Gawlikowsky, quien en una serie de campañas estuvo excavando en el templo de Alat en Palmira, señala (1983: 179) que «la identificación de Atenea con Alat estaba extendida por toda Siria, naturalmente porque el panteón griego no ofrecía otro ejemplo de una diosa de la guerra que correspondiera a la figura de la protectora de los árabes nómadas. Estos veneraban a Alat como a su diosa principal (Al-lath, de al-ilat, «la diosa»)». Pasaría bastante tiempo hasta que Alat fuera reconocida finalmente bajo la figura de la Atenea de los griegos y romanos en Oriente. En efecto, existen inscripcio- nes que atestiguan su identificación con Ártemis ${ }^{3}$, o con una representación de Némesis (Dussaud 1935). El hecho es que, desde su primera aparición histórica en el siglo v a.C. (Herodoto I, 131), Alat es conocida por su carácter múltiple. No solamente fue asociada con la diosa del amor Afrodita, sino que compartió con numerosas divinidades árabes el oficio y los atributos militares ${ }^{4}$.

Alat fue conocida sobre todo por su carácter apotropaico o protector. Podía tenérsela por consorte de Dusares (Dushara) por los nabateos y, en tal condición, era considerada diosa de la fertilidad, al igual que Afrodita en Grecia y Atargatis en Siria (Kindler 1983: 57). Pero también se la podía tener por la diosa patrona de la ciudad de Bostra, y así se la identificaba con Tyche ${ }^{5}$. Atenea-Alat era una divinidad poderosísima, y sus atributos eran el casco, la lanza y el escudo, al igual que Palas-Atenea. «En las monedas de Bostra de Antonino Pío y Marco Aurelio, escribe Kindler, Tyche-Atenea es representada de pie en un templo dístilo, escanciando una libación sobre un altar con cuernos en los ángulos. La diosa lleva todos sus atributos de Palas Atenea, cubierta su cabeza con el casco, apoyándose sobre una larga lanza y agarrando un escudo con su mano. Va acompañada de objetos celestiales (sol o creciente lunar)». Con razón hace notar que el templo dístilo puede referirse sencillamente a la «residencia de la diosa de Bostra», el templo que sobrevivió a la cristianización de la ciudad. En las monedas de Bostra, la representación de Alat militante se había transformado en la de una diosa urbana ${ }^{6}$.

Es evidente, por numerosos hallazgos arqueológicos y epigráficos, que los romanos en la región de la Decápolis y la región del Néguev, así como en el resto del reino de los nabateos, no abolieron sino más bien adoptaron los cultos árabes locales, y entre ellos el de Alat, al que llamaron Atenea. Alat-Atenea continuó siendo la «señora» de la nueva provincia Arabia y especialmente de Bostra, su capital, situada en el Haurán, junto a la frontera oriental de la antigua Decápolis. La epigrafía de aquella región

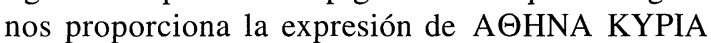
(Kindler 1983), que se puede reconocer como el títu-

${ }^{3}$ Existe en Palmira un altar decorado con volutas, según una inscripción griega fechada el año 6 a.C., en la que se dice «Alat, que es también Artemis» (Gawlikowsky 1983: 181)

${ }^{4}$ Seyrig 1970. En las páginas 111-112, Seyrig menciona una joya inscrita, en la que el dios de la guerra Ares es identificado con dos dioses árabes, Thandr(i)os y Dusares.

5 Así, por ejemplo, en las monedas de ciudad de Bostra (Kindler 1983).

${ }^{6}$ Seyrig (1959: 64) más bien hace resaltar la semejanza entre esta Tyche y la divinidad semítica Gad. 
lo de Alat en su categoría de única y oficial «señora» del país. Este último incluía también, como hemos apuntado antes, el desierto del Néguev, que había formado parte del territorio nabateo, y lo era ahora de la provincia Arabia. Del Néguev proviene justamente otra inscripción, la de nuestra estatua, en la que Atenea recibe igualmente el título de KYPIA.

\section{LA INSCRIPCIÓN}

La inscripción está grabada en tres líneas en la parte anterior de la base de un relieve que representa a la diosa Atenea. Es una inscripción bilingüe, griega y latina. Los caracteres griegos son claros, especialmente en la primera línea, con rayas horizontales entre líneas para ayudar al artífice a mantenerlas rectas. La lectura presenta algunas dificultades, especialmente en las primeras letras de la tercera línea, debido a las abreviaturas:

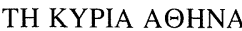
EMOH $\Sigma$ EN (EK T $\Omega N) \mathrm{I}(\Delta \mathrm{I} \Omega) \mathrm{N} \Gamma \mathrm{AIO}(\Sigma) \mathrm{M}(\mathrm{APKO} \Sigma) \mathrm{A}$ NGo" MIL(ES).COH(ORTIS).VI.HISP(ANORUM)

\section{$\Lambda$.}

Siendo una inscripción dedicatoria, el texto contiene naturalmente en primer lugar el nombre y el tí-

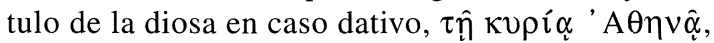
«A la señora Atenea», mientras que el nombre y títulos de la persona que dedica están grabados al final. Entre las dos partes, aquí en la segunda línea, hay un verbo que expresa la acción, la erección de la estatua o relieve, consistente en una sola palabra, غ̇ $\pi$ ó $\sigma \in \mathcal{V}$, «hizo», o sea, «dedicó» 7 . Esta palabra va seguida de dos letras griegas, I y $\mathrm{N}$, que en mi opinión no pueden entenderse más que como abreviatura de la conocida fórmula $\dot{\varepsilon} \kappa \tau \hat{\omega} v i \delta i ́ \omega v$ o $\dot{\varepsilon} \xi i \delta i ́ \omega v$, esto es, «a sus expensas» ${ }^{8}$. Las palabras siguientes son el nombre del soldado al que se refiere la última línea en latín. El nombre abreviado podría ser leído como

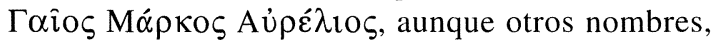

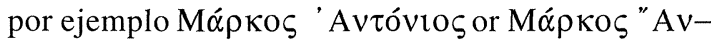
vios (?), podrían ser abreviados de la misma forma.

El punto difícil de la inscripción se encuentra en el grupo de letras que sigue al nombre abreviado al

\footnotetext{
${ }^{7}$ La I desapareció delante de la $\mathrm{H}$, como en inscripciones similares del mismo período. Véase Magie \& Stuart (192: 403), para el caso de una inscripción votiva a Atargatis encontrada en Djrên y fechada en 140 d.C., tercer año de Antonino Pío.

${ }^{8}$ La fórmula se encuentra en muchas inscripciones dedicatorias, especialmente entre las publicadas por la Princeton Expedition to Syria (Magie \& Stuart 1921). Del Néguev conocemos sólo un ejemplo del período prebizantino de la ciudad de Oboda (Avdat): Negev 1981: 20 y 23, inscripción n. ${ }^{\circ} 7$, línea 5 .
}

principio de la tercera línea. Estas letras pueden ser entendidas como continuación de la última $\mathrm{A}$ al final de la segunda línea, y por lo tanto como parte

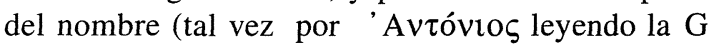
por $\mathrm{T}$ y las dos rayitas por $\mathrm{N}$ ), pero siempre forzando una lectura más directa, cuyo significado por el momento se nos escapa. La dificultad proviene en parte de la presencia de la $\Lambda$ seguida de un punto, debajo de la pequeña $o^{9}$. El grupo podría también ser una indicación cronológica abreviada, como $\dot{\varepsilon} v$ $\mu \eta v i ̀ ~ \Gamma o p \pi \imath \alpha i ́ o v \Lambda$, es decir, «en el día 30 del mes de Gorpiaios». Debemos rechazar la última interpretación por dos razones: la primera es que no se hace mención del año; la segunda es que la continuación inmediata de la inscripción se refiere a quién dedicó la estatua, que es un soldado romano.

El hecho de que esta última parte de la inscripción esté en latín hay que considerarlo como normal, pues es frecuente en las inscripciones dedicatorias de soldados $\mathrm{y}$ oficiales romanos en las provincias orientales ${ }^{10}$. El texto latino no ofrece ninguna dificultad especial en su lectura, a pesar de las abreviaturas y de la forma singular de algunas de sus letras: Miles Cohortis VI Hispanorum, «Soldado de la Cohorte VI de los Hispanos». Estas palabras son importantes, puesto que representan una verdadera novedad en el conocimiento que hasta ahora se tenía respecto a la presencia militar romana en el desierto del Néguev. En efecto, el estudio más reciente sobre el ejército romano en Oriente (Isaac 1990) ponía de relieve la falta de pruebas para establecer la existencia de unidades romanas en el Néguev antes de Diocleciano. Así resumía Isaac el estado de la cuestión:

«No hay acuerdo sobre el período en que el ejército romano estableció por primera vez una organización permanente en el Néguev. S. Aplebaum y M. Gichon arguyeron ... que existía un sistema flavio de defensa que era, de hecho, la continuación de otro anterior, semejante. Tal concepción fue rechazada por Schatzman... Hay que hacer notar que, hasta el presente, no hay fuentes literarias $o$ material epigráfico procedente del Néguev que atestigüe la presencia de unidades específicas antes del siglo IV»"

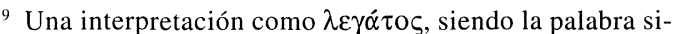
guiente sólomiles, no parece ser adecuada. También podría referirse al $\lambda \imath \theta o v \rho \gamma o ́ s$, al escultor del relieve y grabador de la inscripción, referencia que hallamos en otros casos (véase Abel

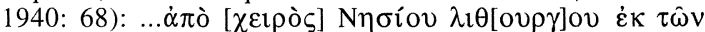
$\imath \delta i ́ \omega \vee \varepsilon \cup ̉ \chi \alpha(\rho \iota \sigma \tau 0 \hat{v} \tau \varepsilon \varsigma)$ en una inscripción que probablemente hay que fechar en el s. II d.C., procedente de Dir el'Balah.

${ }_{10}$ Véase, por ejemplo, Land 1971: 13-14: ... Aur. Marcianus [s]ignifer l[e]g(ionis) voto posuit.

1 Y en nota a pie de página añade: "Exceptuando los epitafios de Mampsis..." (Isaac 1990: 129). Los epitafios en cuestión son dos, y atestiguan la presencia de una guarnición romana en Mampsis (Kurnub, Mamshit). Estudios más recientes que el de Isaac (Millar 1993: 387-400) completan la visión del despliegue militar romano en Palestina durante esta época. 
Por lo que parece, nuestra breve inscripción hace obsoleta esta opinión, puesto que atestigua la presencia de una unidad militar específica, la cohors VI Hispanorum, en un remoto fortín del Néguev, situado en la antigua ruta caravanera de los nabateos que unía la ciudad de Petra, en Transjordania, con Gaza, a orillas del Mediterráneo. Es significativo que aquella ruta estuviese todavía en uso después del siglo i d.C., contrariamente a la opinión de algunos estudiosos, entre ellos A. Neguev (1996). El yacimiento de 'Ein Saharonim, donde fue encontrada nuestra inscripción, fue excavado, pero el informe final no ha sido todavía publicado. El visitante de hoy, sin embargo, puede fácilmente darse cuenta por las ruinas que la excavación puso de manifiesto, que aquel lugar era un fortín originariamente nabateo que fue luego reutilizado por los romanos. Ahora, después del descubrimiento del relieve votivo, uno podría esperarse encontrar allí un lugar de culto, por lo menos un pequeño santuario. Pero nada de ello aparece entre las ruinas actuales ${ }^{12}$. En todo caso, no hay duda de que nuestra estatua constituye un desafío a la opinión, defendida por Isaac, de que «el ejército romano no estaba en este período (esto es, los siglos II y III d.C.) organizado para la defensa de una frontera. No fijó estaciones permanentes en el desierto, sino que estaba establecido en las ciudades de la Decápolis y en Bostra» (Isaac 1990: 131).

Volviendo a nuestra inscripción, la referencia a la cohors VI Hispanorum es importante. Hasta el presente, la única prueba de la existencia de esta cohors y de su situación en Arabia es una inscripción latina de Qasr el Hallabat, fechada en los años 212-213 (Littman \&.Magie 1921: 22-23) ${ }^{13}$. Nuestra inscripción prueba la existencia de una de las unidades en el Néguev, dentro de los límites de la misma provincia Arabia, junto a la antigua ruta nabatea. Se cree, y con razón, que la cohors VI Hispanorum fue más tarde elevada al rango de ala (Speidel 1977: 706). De hecho, el ala VI Hispanorum aparece mencionada en la Notitia Dignitatum como estacionada en Gomoha, en la Arabia de Transjordania ${ }^{14}$. Aque-

12 Una breve noticia sobre la excavación de este yacimiento fue publicada en hebreo por su excavador (Cohen 1982), pero no hace referencia alguna a la estatua de Atenea, puesto que no fue encontrada in situ sino entre las piedras de un pequeño cementerio beduino junto a las ruinas.

13 Pero véase en la colección de diplomas militares (Renier 1976: 113), un diploma de Britania fechado en el período de Adriano, que dice «equitibus et peditibus, qui militaverunt in alis VI et cohortibus XXI, quae apellantur I Hispanorum Asturum, et I Querquernorum, et Picentiana...». No hay nada en la tabla de los diplomas para Siria-Palestina en Reeves (1979).

${ }^{14}$ Notitia dignitatum utriusque imperii. Or. 37, 26 (Seek 1876). lla elevación de rango tiene que haber ocurrido entre los años 212-213 y 395 d.C., que es la fecha más antigua posible para la redacción de la Notitia. De ello se deduce que la estatua fue erigida en una fecha relativamente antigua. Por otra parte, nada prueba que pertenezca a un período anterior a Diocleciano, aunque bien puede creerse así.

\section{LA ESTATUA}

Como ya se ha dicho, es un relieve, naturalmente un altorrelieve más que una verdadera escultura, grabado en piedra caliza. Hoy se conserva sólo fragmentariamente, pues no apareció la cabeza de la diosa. El relieve representa a Atenea en típico atavío de diosa de la guerra, lanza en la mano derecha (la mano misma tampoco se ha conservado), escudo en la izquierda, sobre el que parece apoyarse. Los dos pies salen por debajo de la larga túnica. De la rodilla para abajo, la pierna derecha se percibe como a través de un vestido transparente, y está algo vuelta hacia la izquierda. El vestido de la diosa es una larga túnica de manga corta, que le cae en pliegues sobre los hombros, y la figura va ceñida con un cordón bastante grueso.

Un artista o artífice local trató de imitar en lo posible el tipo clásico de Atenea. Es verdad que la cabeza y su grado de frontalidad nos hubieran dicho hasta qué punto el artista dependía de la tradición local. En un punto, por lo menos, muestra absoluta originalidad. Se trata de lo que normalmente sería el «gorgoneion» o la cabeza de Medusa sobre el pecho de la diosa de la guerra. Es un detalle bien visible en otras representaciones de Alat-Atenea del mismo período en las regiones orientales, tales como una estatua de basalto encontrada en el Haurán y conservada hoy en el Museo de Damasco, que muestra muchas de los rasgos clásicos (Drijvers 1980: 85, fig. 28). Lo mismo puede decirse del bajorrelieve, también procedente del Haurán y hoy en París, de un carácter absolutamente oriental, con dedicatoria en escritura palmirense (Dussaud 1935). Por otra parte, no se ve el «gorgoneion», y posiblemente no exista, en la interesante y muy conocida representación de Alat como diosa guerrera sentada en su trono y flanqueada por dos leoncitos, mientras un donante de pie ofrece incienso a la diosa (Ploix et al. 1933: pl. IV; Seyrig 1970: pl. LVII, fig. 5).

Volviendo al «gorgoneion» sobre el pecho de la representación de Atenea en el Néguev, nos damos cuenta de que lo que el escultor quiso producir no es tanto la cabeza más o menos humana de Medusa, caracterizada por una abundante cabellera, sino 
una cabeza cuadrada con ojos, nariz y boca estilizados. De la línea inferior del cuadrado que forma la cara, sale una especie de brazo o de mano, que parece como alargada en actitud amistosa. En nuestra opinión, a pesar de la rudeza y falta de precisión lo que se intentó representar fue una especie de betilo nabateo, un representación cuadrada de la divinidad, o mejor dicho, de la piedra que sería su soporte material. Creemos que, con este rasgo extraño de lo que normalmente sería el «gorgoneion» de Atenea, el autor del relieve ha querido volver a la tradición local, puesto que alude a una representación típica de la diosa árabe ${ }^{15}$. Atenea y Alat se fundieron en una. Al carácter militar de la primera se unieron las tendencias más bien humanas de la segunda.

Betilos representando a Alat y acompañados de inscripciones nabateas han sido encontrados en las rocas que rodean un santuario de la diosa en el Wadi er-Ram. Fueron publicados por el M.R. Savignac (1933: 411) en su informe sobre la visita realizada al lugar en los años $1930^{16}$. Es evidente que tales betilos son de un período anterior al de nuestra estatua, muy probablemente de los últimos años del reino nabateo independiente. Aquellos textos identifican explícitamente el betilo no sólo como Alat, sino también como «Alat de Bosra (Bostra)»:

«Esta es la diosa Alat de Bosra

... que ha hecho Thaimallahi...»

Probablemente Savignac tenía razón al suponer que durante el reinado de Rabbel II, Bostra fue elevada al rango de capital, y que en consecuencia sus divinidades empezaron a recibir culto en otros lugares remotos. Alat de Bostra tenía un santuario particular en El-Ram. Otros dioses, tales como A'ara de Bostra, tenían santuarios y betilos en Medain Saleh (Hegra), en la parte más inferior del reino (Savignac 1934: pl. XXXVIII-XXXIX). Nada nos impide pensar que el descubrimiento de una representación de Atenea-Alat en el Néguev pueda también significar la presencia de un lugar dedicado al culto. Sin embargo, como ya hemos dicho antes, la excavación del fuerte romano-nabateo de 'Ein Saharonim, una típica estación caravanera a lo largo de la difícil ruta entre Petra y Gaza, no fue publicada enteramente, y es por lo tanto imposible de verificar.

Pero es mucho más importante, en nuestra opi-

15 Pendientes en forma de diminutos betilos fueron publicados por Patrich (1983). Su insistencia en llamarlos representaciones de $\mathrm{El}$ 'Uzza podría ser puesta en duda, puesto que también otras diosas podrían haber sido representadas en la misma forma.

16 Un estudio posterior de aquel templo (Kirkbride 1960) llega también a la conclusión de que fue probablemente edificado hacia finales del reinado de Rabel II.

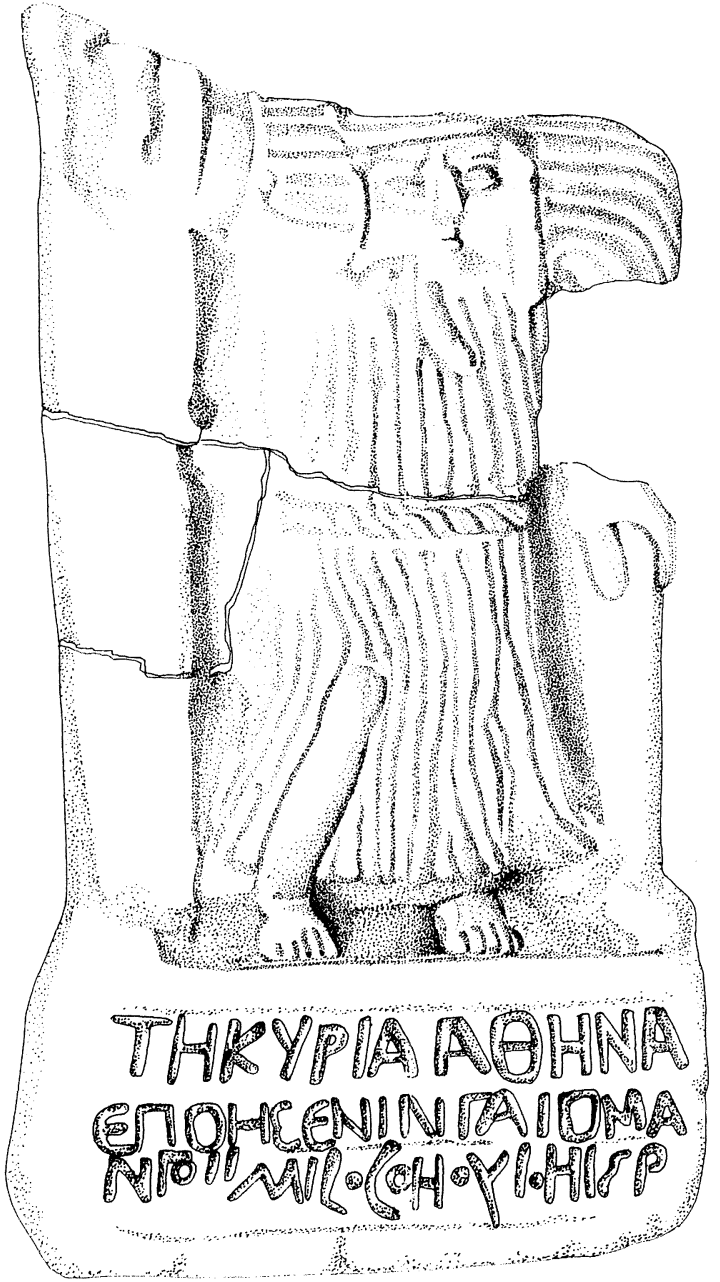

nión, darse cuenta de que es un soldado romano quien dedica la estatua a la diosa Atenea. Y no es una estatua cualquiera, sino que ostenta una señal inequívoca de identificación con la diosa árabe Alat, considerada como la patrona y señora del país. En su falta de destreza, el escultor ha producido una extraña combinación de las diosas griega y árabe, de tal modo que la figura parece mostrar un equilibrio entre la fuerza militar y el cuidado por los humanos que buscan la protección divina.

La mano que sale de la figura, divina y casi paternal, tiene un significado en su gesto generoso. Es posible que el inexperimentado artista tuviese en la mente las manos alzadas del betilo de Alat que nos es conocido del El-Ram ${ }^{17}$. En todo caso, el hecho de que el donante de la estatua sea un soldado romano, esto es, un representante de la autoridad reinante ex-

17 Según Savignac (1934), este rasgo no debe confundirse con el creciente lunar representado en el betilo que él reproduce en pl. XXXIX y fig. 7. 
tranjera que había anexionado el territorio de Alat al imperio romano, no sólo es una indicación de la fusión espontánea de culturas y religiones entre dos pueblos, sino también una posible indicación de un interés real por adoptar el culto de los dioses locales. ¿Habría que considerar esto como una política oficial de las autoridades romanas hacia la población local en las provincias orientales? No lo sabemos. Más tarde, durante la administración bizantina, las autoridades iban a basar su confianza en los pueblos nómadas recientemente sometidos sólo bajo la garantía de su conversión oficial al cristianismo ${ }^{18}$, esto es, a la religión oficial del imperio. El mismo desierto del Néguev se convirtió al cristianismo, y los adoradores locales de los antiguos dioses nabateos como Alat tuvieron que consentir en aceptar el nuevo culto, según nos cuenta explícitamente Jerónimo en su Vita Hilarionis ${ }^{19}$. Aquí, por el contrario, somos testigos de la actitud contraria, la de un soldado romano adoptando una divinidad árabe local como objeto de su culto. ¿Podemos creer que no fue éste un ejemplo casual de la tolerancia romana de cultos locales, sino más bien una indicación de una política de absorción de la población local por medio de la adopción formal de sus divinidades? La pregunta queda por el momento sin respuesta.

\section{BIBLIOGRAFÍA}

Abel, M.-F., 1940: «Les confins de la Palestine et de l'Egypte à l'âge des Ptolémées», Revue Biblique 49: 68.

Cohen, R., 1982: «Metzad Sha'ar Ramon», Hadashot Arkheologyiot 80-81: 52-53 (en hebreo).

Cumont, F., 1924: «Une dédicace à des dieux syriens trouvée à Cordoue», Syria 5: 342-345.

DriJvers, H.J.W., 1980: «De Provincia Syria. Grieks-Romeinse beschaving in het Nabije Oosten», Phoenix 26/2: 72-93.

Dussaud, R., 1935: «Les déesses Allat-Athéna et Simia», Syria 16: 323-324.

Gawlikowsky, M., 1983: «Le sanctuaire d'Allat à Palmyre, Aperçu préliminaire», Les Annales Archéologiques Arabes Syriens 33/I: 179-189.

\footnotetext{
18 Son bien conocidos los ejemplos de esta política, como por ejemplo la conversión de la reina Mawia y su tribu beduina durante el reinado de Teodosio II (Sozómenos, Hist. Eccl. VIII, 38, PG 67, 1408-1411).

19 Vit. Hil. 25 (PL 23, 42). Es posible que la diosa a que se refiere este pasaje, que trata de la visita de Hilarión a Elusa (unos $65 \mathrm{~km}$ al noroeste de 'Ein Saharonim, en la misma vía de Petra a Gaza), bajo el nombre de «Venus», fuera de hecho Alat, la diosa celestial que tenía tales atributos como el sol, las estrellas y el creciente lunar.
}

IsAAC, B., 1990: The limits of empire: the Roman army in the East, Oxford.

KindLER, A., 1983: The coinage of Bostra, Warminster.

KirkBride, D., 1960: «Le temple nabatéen de Ramm. Son évolution architecturale», Revue Biblique 67: 65-72.

LAND, E., 1971: Corpus monumentorum religionis dii Menis I: The Monuments and Inscriptions, Leiden.

Littman, E. \& Magie, D., 1921: The Ledja (Syria, Publications of the Princeton University $\mathrm{Ar}$ chaeological Expedition to Syria in 1904-5 and 1909, Div. III), Leiden.

Magie, E.L.D. Jr. and Stuart, D.R., 1921: Greek and Latin Inscriptions, Section Southern Syria (Syria, Publ. Princ. Univ. Archaeol. Exped. to Syria in 1904-5 and 1909, Div. III), Leiden.

Mildenberg, L., 1990: «Rebel Coinage in the Roman Empire», in Greece and Rome in Eretz Israel-Collected Essays (ed. A. Kasher, U. Rappaport \& G. Fuks), Jerusalem, 62-74.

Millar, F., 1993: The Roman Near East (31 BC 337 AD), Harvard.

Negev, A., 1966: «The Petra-Gaza Road», Palestine Exploration Quarterly 98: 89-98.

NEGEV, A., 1981: Greek Inscriptions from the Negev, Jerusalem.

PATRICH, Y., 1983: «Earrings of the Goddess El Uzza from Mampsis», Qadmoniot 16: 86-88 (en hebreo).

Ploix de Retrous, G., and Seyrig, H., 1933: «Khirbet el-Sané», Syria 14: 12-19.

ReEves, C.N., 1979: «A New Diploma for Syria-Palestine», Zeitschrift für Papyrologie und Epigraphie 33: 117-123.

RENIER, L. (ed.), 1876: Recueil de diplomes militaires, Paris.

SARTRE, M., 1984: «Le dies-imperii de Gordien III: une inscription inédite de Syrie», Syria 61: 49-61.

SAVIGNAC, M.R., 1934: «Chronique. Le sanctuaire d'Allat à Iram (suite)», Revue Biblique 43: 572589.

SeEK, O. (ed.), 1876: Notitia dignitatum utriusque imperii, Berlin.

Seyrig, H. 1959: «Temples, cultes et souvenirs historiques de la Décapole», Syria 36: 60-71.

Seyrig, H. 1970; «Antiquités syriennes. 89. Les dieux armés et les Arabes en Syrie», Syria 47: 78-112.

SPEIDEL, M.P., 1977: «The Roman Army in Arabia», in Aufstieg und Niedergang der Römischen Welt, II, Principat (ed. H. Temporini \& W. Haase), Berlin-New York, 689-730. 